\title{
GÊNEROS TEXTUAIS E TRANSMIDIAÇÃO: APROXIMAÇÕES, POTÊNCIAS E DESAFIOS PARA A EDUCAÇÃO
}

\author{
D. LIMA ${ }^{1,{ }^{*}}$, A. VERSUTI ${ }^{2}$, R. BENIA ${ }^{3}$ \\ ${ }^{1}$ Universidade Federal de Alagoas, ${ }^{2}$ Universidade Federal de Goiás, ${ }^{3}$ Universidade Federal de Sergipe \\ daniellalima90@gmail.com*
}

Submetido 16/06/2016 - Aceito 14/06/2018

DOI: $10.15628 /$ holos.2018.4723

\section{RESUMO}

O presente artigo tem como discussão central a inserção de elementos da Narrativa Transmídia no processo de aprendizagem, mais especificamente na aprendizagem de Gêneros Textuais. Para isso, apresenta-se uma fundamentação teórica para a reflexão do conceito de Narrativa Transmídia, bem como dos Gêneros Textuais, sendo enfatizada a Crônica, gênero utilizado para o desenvolvimento da atividade. Diante disso, têm-se como objetivos refletir acerca dos conceitos de Narrativa Transmídia e Gêneros textuais; e investigar como acontece a aprendizagem do gênero textual crônica por meio de elementos da transmídia a partir de uma atividade prática de produção deste gênero junto a alunos do curso de Comunicação Social Jornalismo. Para chegar aos objetivos, utilizou-se, na metodologia da pesquisa, a pesquisa bibliográfica e as pesquisa-ação, esta última utilizada na parte prática do trabalho. Assim, foi planejada e desenvolvida uma atividade envolvendo elementos da transmídia e a produção do gênero textual crônica. Por fim, com essa atividade, coletaram-se resultados os quais afirmaram que o uso dos elementos da transmídia contribuiu para a aprendizagem do gênero trabalhado, por meio do engajamento e autoria proporcionados pelo processo.

PALAVRAS-CHAVE: Aprendizagem, Crônica, Narrativa transmídia.

\section{TEXT GENRES AND TRANSMEDIATION: APPROACHES, POTENCIES AND CHALLENGES FOR EDUCATION}

\begin{abstract}
This paper aims to discuss the insertion of Transmedia Narrative elements and learning process, specifically in learning Text Genre. For this, we present a theoretical basis for the reflection of the concept of Transmedia Narrative and the Text Genre, and emphasized the Chronicle, gender used for the development of the activity. Therefore, it has as objective to reflect about the concepts of Transmedia Narrative and Text genres; and it investigates how learning takes place the chronic genre through transmedia elements from a practical activity of
\end{abstract}

production of this genre with students of the Social Communication course - Journalism. To reach the goals, it was used in the research methodology, the bibliographical research and action research, the latter used in the practice of labor. Thus, it was planned and developed an activity involving elements of transmedia and production of chronic genre. Finally, with this activity, we collected up results which stated that the use of transmedia elements contributed to the learning worked gender, through the engagement and authorship provided by the process.

KEYWORDS: Learning, Chronicle, Transmedia narrative. 


\section{INTRODUÇÃO}

Enquanto princípio basilar, a comunicação sempre permeou as atividades e as relações entre os sujeitos apontando implicações em diversas facetas, quer seja na vida social, subjetiva, profissional ou educativa, sobretudo. Para tanto, configura-se igualmente como o fator que levanta um proeminente reflexo no desenvolvimento do sujeito, na medida em que se tem em foco o diálogo deste com máquinas, ou entre outros sujeitos presentes ou tangenciados no processo.

Perante essa assertiva, a comunicação que aponta novos desdobramentos sem anular ou afetar negativamente outras práticas anteriormente efetivadas, nasce sob a égide de uma necessidade iminente que o sujeito abarca de executar atividades que são inerentes ao seu subjetivo ou demanda social. $\mathrm{O}$ fato espelhado é que a comunicação traduz diversas possibilidades férteis, e conquanto, promissoras para alguns eixos, tais como na Educação.

Com efeito, as tecnologias de comunicação em união às mídias denotam transformações densas e expressivas no que compete o âmbito cultural, comportamental. A esse ângulo abrigamse novas facetas presentes em atividades que o sujeito põe em foco, tais como, a comunicação com outros sujeitos ou a busca de informações e publicação de conteúdo - sobretudo, do seu próprio conteúdo. Pensando na perspectiva de consumo, produção, compartilhamento e troca de conteúdos, ações estas facilitadas pelas tecnologias e as diversas mídias que surgem com elas, tem-se a ideia de que o uso dessas ferramentas e dos recursos que estas proporcionam, apresente terreno significativo para práticas educativas.

Dessa maneira, defende-se que o cenário que engloba as mídias e as tecnologias apresenta oportunas vantagens para o campo educacional. As mídias cercam os sujeitos e, constantemente, o diálogo entre mídias e sujeito apresenta-se decisivo no campo do conhecimento. Ainda que a realidade do sujeito seja consistida pela comunicação entre sujeitos, em essência, também é uma realidade na qual as mídias estabelecem expressiva presença.

Essa realidade assume uma perspectiva na qual a comunicação entre os sujeitos acontece de maneira instantânea, independente de espaço físico ocupado por estes. Com as mídias, em acréscimo à internet, a presença física translada a um nível mais amplo, pois, em essência, é superada pela presença digital que quebra as barreiras da distância e premia a acessibilidade e rapidez das informações.

É justamente esse contexto que cerca a cibercultura. Mas, sobretudo, a cibercultura remete ao surgimento de um universo constituído por comportamentos, técnicas intelectuais e práticas, ideologias e pensamentos diferentes do mundo físico. Esses fatores que compõem a cibercultura são enaltecidos com o crescimento do ciberespaço. A cibercultura, nesse sentido, expressa a presença de espaço em soma com os comportamentos presididos nele, que anula distâncias, aproxima pensamentos, acelera construções e disseminações de ideias, pressupondo, assim, diversas mudanças no âmbito social em qualquer parte do mundo. (LÉVY, 2007). 
Parece conveniente ressaltar que, diante dessa ótica, os processos comunicativos manifestaram aspectos que enveredaram a novas práticas on-line. Ainda sobre a cibercultura, Lemos (2002) assinala-a como um fenômeno que expõe um panorama da relação entre o sujeito social e as tecnologias de informação. Incide, nesse sentido, transformações na cultura da comunicação desses sujeitos que vivem nesse contexto.

A cultura colaborativa é um dos aspectos mais proeminentes localizados no bojo da cibercultura. As informações não são somente adquiridas ou buscadas, mas são tomadas como fruição e se tornam produtos novos em conteúdos que são elaborados deliberadamente pelos sujeitos, comportando assim, um teor mais libertador e substancial. Esses sujeitos, então, virão produtores dentro desse ciberespaço. Por produtores, neste espaço, Castells (2001) refere-se aos sujeitos que retroalimentam o sistema tecnológico por meio do uso da internet. Esse impacto da possibilidade de construção e emissão da informação reside também nos processos interativos que são presididos em rede e que são envoltos à realidade desses sujeitos na cibercultura.

Ao refletir sobre isso, lembra-se que, dentro dessa conjuntura instaurada, é preciso também haver uma formação pertinente dos educadores. É preciso, portanto, que novas práticas dos sujeitos sejam dialogadas também no ambiente formal de sala de aula, não se restringindo apenas ao campo informal em sociedade. Se por um lado, as mídias contornam os sujeitos, por outro lado, é preciso estar apto a lidar e utilizá-las de forma proveitosa. (MORAN, 2007).

Diante deste contexto, pode-se afirmar que a partir da interação dos sujeitos imersos nessa cultura colaborativa há a construção de conhecimento e, consequentemente, concretiza-se a aprendizagem. Assim, acredita-se que se por meio dessas relações os sujeitos aprendem, conhecimento considerado informal, podem também aprender conhecimento formal se tais práticas forem aderidas pelas instituições escolares no processo de ensino aprendizagem.

Pensa-se na sociedade em rede apresentada por Castells (2005). Segundo este autor, a sociedade em rede possui uma característica central e que remete ao que está sendo discutido, que é a transformação da área da comunicação. Ainda de acordo com o autor, a comunicação, assim, constitui-se como um espaço público, no qual os sujeitos recebem informações e constroem seus pensamentos acerca destas informações recebidas. Posto isso, é relevante destacar a caracterização de conjunto, entre os sujeitos imersos nesse espaço, remetido nessa característica citada.

As mudanças citadas anteriormente remetem ao fluxo de conteúdos em rede e de como isso implica nas novas práticas. Dessa maneira, afirma-se que a escrita e a leitura vêm configurando novas aparências em razão deste panorama. Ao passo disto, em acréscimo à acessibilidade, fruição do conteúdo e disseminação deste conteúdo, os sujeitos vivem experiências expressivas que evocam aspectos positivos para a educação. A transmidiação é corporificada e está estritamente agregada a esse campo.

Por transmidiação entende-se o fenômeno da transição de um conteúdo por diversas mídias, que surge de algum já criado e adiante se apresenta em cada plataforma por um viés de linguagem diferente e pertinente a cada mídia que o abriga. (GOSCIOLA, 2012). A essência das 
narrativas transmídias é que um conteúdo seja expandido e igualmente apresente características suficientes para que o sujeito entenda o contexto geral sem precisar recorrer a um conteúdo original.

Novos caminhos são corporificados para uma história inicial, e, são esses caminhos que apresentam uma ligação diretamente densa com a história original. Tais narrativas transmídias designam conteúdos que surgem a partir de outros já criados, mas na medida em que contornam novas atribuições estabelecidas a estes. Com isso, é possível que estas narrativas venham a conferir maior flexibilidade aos conteúdos em rede, e em especial, às dinâmicas envoltas ao processo de aquisição, produção e disseminação de informações.

A união de um mundo já elucidado (quer seja informal ou não) com o mundo que será criado pressupõe um viés promissor ao sujeito, uma vez que se põe em foco a imaginação, o juízo moral e o juízo estético. Tal como propõe Argan (1999) ao relatar sobre a avaliação do conteúdo visual imagético e a produção destes. Assim, tem-se a atividade de (re)construção como algo que põe em foco não somente a análise e a observação, mas o poder e habilidade de criação e pensamento mais aguçado. Sendo um suporte para outras atividades, tais como a leitura e produção textual, bem como a inserção de conteúdos formais nestas atividades citadas.

Por fim, o artigo apresenta, por meio de uma abordagem qualitativa, os resultados de uma pesquisa-ação feita com alunos do curso de graduação em Comunicação Social - Jornalismo. A pesquisa realizada teve como objetivo investigar como acontece a aprendizagem do gênero textual crônica por meio de elementos da transmídia a partir de uma atividade prática de produção deste gênero junto a esses alunos.

Para isso, utilizou-se como metodologia, além da pesquisa bibliográfica para conceituar os temas destacados, a pesquisa-ação. Os instrumentos utilizados na pesquisa-ação foram: um instrumento criado pelas pesquisadoras no intuito de avaliar a crônica desenvolvida pelos alunos e um questionário estruturado aplicado em dois momentos; antes e depois da atividade, para que os resultados fossem comparados.

De acordo com Tripp (2005), a pesquisa-ação tem como uma das características deixar registrado o desenvolvimento de um processo pensado e aplicado em determinada área, a fim de documentar resultados de testes. No caso deste estudo, utilizou-se a pesquisa-ação no intuito de aplicar uma atividade relacionada a aprendizagem do Gênero Textual Crônica e registrar os resultados alcançados, a fim de contribuir com a área da educação.

A relevância deste estudo se dá pelo fato de que os Gêneros Textuais são necessários para a interação dos sujeitos, já que em qualquer momento de comunicação, verifica-se a utilização de pelo menos um gênero. Concluiu-se que a Narrativa Transmídia por ter esse papel de disseminação de conteúdos de determinado universo narrativo, faz uso de diferentes Gêneros Textuais, o que torna possível utilizar elementos transmídia na proposição de atividades nas quais os sujeitos possam expandir/desdobrar histórias em diferentes tempos e espaços, potencializando assim a aprendizagem do Gênero Textual Crônica. 


\section{PENSANDO A NARRATIVA TRNSMÍDIA E O CONTEXTO ATUAL DA EDUCAÇÃO}

As relações provenientes dos encontros entre sujeitos no meio social trazem a necessidade destes se comunicarem para expressar sentimentos, pensamentos, ideias. A comunicação é imprescindível para a convivência entre os seres em suas redes na sociedade. E para a concretização dessa comunicação, há um elemento chave por meio do qual esses sujeitos expressam-se da melhor maneira a compartilhar sua mensagem, a linguagem.

A vida em sociedade sempre exigiu de seus participantes a comunicação, independente de como se dá esse processo. Em cada momento histórico, em cada contexto social, há diferentes maneiras utilizadas pelos sujeitos no intuito de concretizar o processo comunicacional. Como elucida Rousseau (1998), o sujeito foi reconhecido por outro como ser sensível, pensante e parecido a si próprio, assim, por meio do desejo e a necessidade de comunicar seus sentimentos e pensamentos fizeram-no buscar meios para isto. A linguagem, como artefato variante para a comunicação entre sujeitos, deve ser considerada como um desses meios. Variante, pois ocorre de diferentes formas, adequando-se a diferentes contextos como, históricos, sociais, culturais.

Diante disso, vale elucidar que os seres se comunicam entre si por outros meios e não só pelas palavras. Os gestos, as imagens, os sons informam algo, ou seja, comunicam, no entanto, varia de acordo com diferentes culturas. (CAUNE, 2014). Historicamente e culturalmente, a linguagem e a comunicação estão entrelaçadas de tal forma que uma não se completa sem a outra, pois não é possível comunicar algo sem utilizar uma linguagem, ou ainda, utilizar uma linguagem sem comunicar nada. Linguagem e comunicação sempre fizeram parte das relações sociais.

[...] a comunicação não se dá sem uma forma de linguagem, pelo contrário, existe uma relação muito íntima entre as duas e que torna realizável aquilo que se quer expressar. Afinal, para se comunicar algo é preciso um tipo de linguagem e ao se usar qualquer forma de linguagem comunica-se algo. (SANTANA, 2002, p. 16).

À vista disso, por comunicação, entende-se, processo pelo qual há transmissão e recepção de mensagens entre emissor e receptor, no qual as informações são passadas por meio de recursos característicos do ser humano ou de aparelhos e dispositivos técnicos. Essas mensagens são codificadas pelo emissor e decodificadas pelo destinatário, por meio da utilização de sistemas de signos ou símbolos sonoros, escritos, iconográficos, gestuais etc. (NEIVA, 2013).

Por meio da comunicação, os sujeitos interagem nas comunidades sociais em que vivem. Como afirma Penteado (1987, p. 1), "comunicação é convivência; está na raiz da comunidade, agrupamento caracterizado por forte coesão, baseada no consenso espontâneo dos indivíduos". Sendo assim, a comunicação está relacionada à socialização, interação, informação, conhecimento, aprendizagem, compartilhamento das e entre comunidades sociais.

Isto posto, sabe-se que acontecem mudanças na sociedade, com isso, as linguagens e as maneiras de comunicação também se modificam. Essas mudanças não são simples transformações nos modos de comunicação, são mudanças culturais que acontecem nas comunidades sociais. As necessidades e vontades dos sujeitos de expressar-se e comunicar-se são 
as mesmas, o que muda são as formas como acontece o processo. Outras linguagens aparecem, os meios e formas de comunicação inovam-se, assim, a cultura do sujeito social acompanha essas alterações. Modifica, assim, o modo de como se dá o processo de comunicação entre os sujeitos.

Toda comunidade possui costumes, crenças, culinária, músicas, entre outros componentes específicos, o que denominamos cultura de determinado grupo. Apesar de existir entre diferentes grupos esses fatores específicos, a cultura sofre mudanças, é dinâmica, pois se adapta às transformações que acontecem na sociedade. Perdem-se certas características e se ganha outras, tudo isso em diferentes velocidades e em sociedades distintas.

Macedo (2012) afirma que existem duas vertentes básicas que admitem a mudança cultural: a introdução de novos conceitos, bem como a propagação de conceitos a partir de outras culturas. E há também a descoberta, com esta a mudança origina-se por meio da revelação do desconhecido pela sociedade que a adota. Com as possibilidades de transformação da cultura, uma dessas vertentes, a introdução de novos conceitos aos que já existem, aproxima-se do que é denominado Culturas Híbridas.

Compreendem-se culturas híbridas como sendo a junção do que já existe de cultura de um determinado povo, com o que chega de novo para agregar a essa cultura. Ou ainda, cita-se como fonte para a hibridação cultural, a adesão de pontos culturais de outra comunidade, havendo assim a fusão da cultura local com a cultura "do outro". Canclini, ao delinear o termo Culturas híbridas, pensou em ocupar-se do entrelaçamento entre os usos populares e cultos, os meios massivos de comunicação e dos processos de recepção e assimilação dos bens simbólicos. (GAGLIETTI; BARBOSA, 2007).

Meu propósito foi elaborar a noção de hibridação como um conceito social. Como expliquei em Culturas híbridas, encontrei neste termo maior capacidade de abarcar diversas mesclas interculturais do que com mistura, limitado às que existem entre raças, ou sincretismo, fórmula referida quase sempre a funções religiosas ou de movimentos simbólicos tradicionais. Pensei que necessitávamos de uma palavra mais versátil para dar conta tanto dessas misturas "clássicas" como dos entrelaçamentos entre o tradicional e o moderno, e entre o culto, o popular e o massivo. (CANCLINI, 1997, p. 111 - Tradução nossa). ${ }^{1}$

Logo, entende-se que a cultura é aberta a transformações. A ela são incorporadas novas características de acordo com as mudanças sociais, bem como pode haver fusão de características de culturas distintas. Com isso, destaca-se a chegada, introdução e difusão da internet, bem como de novos meios e mídias de comunicação em todos os contextos da nossa sociedade.

1 “Mi propósito ha sido elaborar la noción de hibridación como un concepto social. Según lo expliqué en Culturas híbridas, encontré en este término mayor capacidad de abarcar diversas mezclas interculturales que con el de mestizaje, limitado a las que ocurren entre razas, o sincretismo, fórmula referida casi siempre a funciones religiosas o de movimientos simbólicos tradicionales. Pensé que necesitábamos una palabra mas versátil para dar cuenta tanto de esas mezclas "clásicas" como de los entrelazamientos entre lo tradicional y lo moderno, y entre lo culto, lo popular y lo masivo." (CANCLINI, 1997, grifo do autor, p. 111). 
Em boa medida, a sociedade mudou muito antes de a web nascer, porém, é inegável o papel desses novos modos de comunicação no processo de transformação social e cultural em que se vive hoje. Estes invadiram uma sociedade que tinha uma determinada cultura, entrelaçando-se a ela e transformando-a. Muda-se também o modo como acontece a comunicação entre os sujeitos sociais.

Ao refletir sobre isso, elucida-se que na sociedade atual, a comunicação vai além da fala, leitura e escrita, em tempos de interação, inovações nos meios de comunicação, troca e compartilhamento de informações contínuas, considera-se que a cultura dos sujeitos mudou e segue mudando. Nessa cultura atual, a comunicação acontece por meio de diferentes linguagens presentes em diferentes plataformas de mídia.

E, o sujeito que está presente nesse contexto atual, faz uso de linguagens que surgem com o desenvolvimento das tecnologias. As plataformas dão suporte para isso e os sujeitos engajam-se cada vez mais nessas novas maneiras de se comunicar. O Whatsapp, o Instagram, o Facebook, o Google +, o Youtube, o Twitter, são exemplos de plataformas que disponibilizam diferentes linguagens possíveis para a comunicação entre seus usuários.

$O$ século $X X$ viu o telefone, o cinema, o rádio, a televisão se tornarem objetos de consumo de massa, mas também instrumentos essenciais para a vida cotidiana. Enfrentamos agora o fantasma de mais uma intensificação da cultura midiática pelo crescimento global da Internet e pela promessa (alguns diriam ameaça) de um mundo interativo em que tudo e todos podem ser acessados, instantaneamente. (SILVERSTONE, 2002, p. 17).

Nessa cultura midiática, como o próprio termo enfatiza, a mídia, enquanto centro, serve como suporte de produção cultural, bem como pela inter-relação que há no processo dessas produções culturais. Essa cultura surge com o desenvolvimento da Sociedade de Informação, que contempla a troca e compartilhamento de informação e conhecimento. (PORTO, 2012). A cultura midiática contempla a criação/produção de conteúdo em suportes midiáticos, bem como a interconexão que pode haver entre esses conteúdos.

O fluxo de informações da cultura midiática é contínuo, assim como a participação dos sujeitos integrantes dessa cultura. Vale lembrar o novo formato de sujeito que aparece nesse panorama: no qual o consumidor que também é produtor, conforme os conceitos PRODUSSUMIDOR de Décio Pignatari (1969, p. 31-32), PROSUMER de Alvin Toffler (1980, p. 11) e PRODUSER de Bruns Axel (2008, p. 2). Prova disso é o sucesso dos blogs que não perderão o lugar para outros tipos de comunicação, no máximo mudarão de nome, como Tumblr. (VERSUTI; GOSCIOLA; LIMA, 2014).

Essas denominações, enfatizadas por esses autores, caracterizam o sujeito ativo em relação ao consumo de conteúdos ou produtos na cultura da qual fazem parte. Observa-se que não é só neste século que consumidores estão assumindo papel de produtores também. A denominação para estes já existia em 1969, como conceituou Pignatari. Após, surgiram outras denominações, mas a característica principal era a mescla de consumir e produzir, sujeitos que não aceitam ser apenas consumidores passivos. Assim, estes produzem produtos e conteúdo baseados no que foi consumido, ou não. 
A denominação sofre mudanças, assim como os meios e mídias nos quais essas produções são compartilhadas. Na cultura atual, em que mídias exercem influência sobre os sujeitos, os prosumidores consomem e compartilham conteúdos em diferentes plataformas. Como elucida Silverstone (2002, p. 46), "novas tecnologias, novas mídias, cada vez mais convergentes pelo mecanismo da digitalização, estão transformando o tempo e os espaços sociais e culturais". As inovações nas mídias e nos meios de comunicação estão transfazendo a maneira como os sujeitos consomem e produzem conteúdos, tendo a possibilidade de acesso mais abrangente e a oportunidade de atingir um maior número de sujeitos.

Com isso, o contexto atual de interação e colaboração entre sujeitos culturais contempla o conceito de Narrativa Transmídia como a arte de criação, distribuição e exibição de um universo narrativo. Este, amplia e enriquece a experiência narrativa, seja ela para o entretenimento, para a informação, para o comércio, para a educação.

Henry Jenkins define a Narrativa Transmídia como uma história expandida e dividida em várias partes que são distribuídas entre diversas mídias. (JENKINS, 2009). Narrativa Transmídia é uma estratégia de comunicação, que organiza conteúdos e plataformas para contar uma história. (GOSCIOLA; VERSUTI, 2012). Tal estratégia determina qual plataforma será indicada para a história principal e quais outras serão utilizadas pelas histórias complementares.

Neste processo, cada mídia contribui de maneira própria e específica para o desfecho, construindo uma experiência coordenada e unificada de entretenimento. (MARTINS, 2009). Essas narrativas atravessam diferentes mídias a partir das quais é possível criar um universo ficcional expandido ao redor da obra. Não é apenas o conteúdo que migra nesse processo, por isso é necessário um planejamento transmidiático atento a cinco elementos fundamentais (história, audiência, plataformas, modelo de negócio, execução) e que prima por utilizar as potencialidades e os recursos específicos de cada meio na ampliação da experiência do sujeito com o conteúdo ficcional exposto. Já que, "cada meio ou plataforma de comunicação gera diferentes experiências - cognitivas, emotivas, físicas - de uso, cada meio tem sua especificidade". (SCOLARI, 2013, p. 83).

Outro fator importante parece suscitar diante deste cenário. É fundamental refletir sobre a forma como esta cultura participativa está revitalizando o processo tradicional de construção do conhecimento. Importante também observar como os educadores estão reavaliando o valor da educação informal e como os sujeitos estão aplicando as suas habilidades como coprodutores em diferentes instâncias sociais: trabalho, família, escola e política.

Entendido o papel singular que os veículos de comunicação passaram a exercer no mundo contemporâneo, agora com o aporte dos novos meios disponibilizados pela informática, pelos sistemas digitais, pelas redes de computadores, e que orientam uma revolução nos diferentes âmbitos formal, tenha se recolocado numa perspectiva diferenciada e que requisita, de maneira crescente, o estreitamento dialógico com informações e conhecimentos gerados em fontes indiretamente escolares. (CITELLI, 2004, p. 137).

A prática de construção de conhecimento de forma participativa e colaborativa cresce entre os sujeitos agentes diante desse novo cenário da comunicação. Muda-se o cenário educacional, os sujeitos passam a ser autores de sua própria aprendizagem. A educação em meio a cultura digital deve ter docentes conscientizados de que são mediadores da aprendizagem, 
deixando o discente autônomo para buscar e construir seu conhecimento na diversidade de meios disponíveis, sejam eles digitais ou não.

Posto isso, aclara-se a ideia de autonomia apresentada por Freire (2011), esta, considerada como o amadurecimento do ser para si, dessa maneira, entende-se que é por meio de um processo moldado por experiências em que o sujeito se torna autônomo. Nesse sentido, deve estar atrelada à "pedagogia da autonomia", por meio de experiências que estimulam a decisão e a responsabilidade do sujeito, engajando-o, dessa forma, em experiências de liberdade. Pois, defende-se a ideia de que os docentes devem "[...] saber que ensinar não é transferir conhecimento, mas criar as possibilidades para a sua própria produção ou a sua construção. [...]". (FREIRE, 2011, p. 47).

Dessa maneira, revela-se o potencial do uso de elementos da Transmídia na Educação. Uma vez que os sujeitos, por meio deles, podem criar histórias baseadas em outras, ou ainda modificá-las, fazendo uso de sua autonomia. Estes sujeitos leem, imaginam o que leem, criam como poderia continuar a história lida, ou ainda modificá-la. Diante desse panorama, duas coordenadas podem definir as Narrativas Transmídia, expansão de uma história por intermédio de vários meios e colaboração dos usuários nesse processo expansivo. (SCOLARI, 2013). A criação de histórias e disponibilização destas em diferentes mídias por leitores, com base em uma determinada narrativa original, também a torna Narrativa Transmídia.

Como afirma Andrea Phillips (2012, p. 13), “as histórias no processo transmidiático são, levemente, entrelaçadas. Cada uma pode ser consumida por si só e o leitor/espectador tem a ideia de que foi lida/assistida uma história completa". Com isso, detém-se mais especificamente, no potencial de propostas metodológicas e de elaboração de conteúdos digitalmente expandidos que permitam uma compreensão ampliada de significado, independentemente dos caminhos da leitura e, que, ao mesmo tempo, garantam ao sujeito em contato com uma parte da narrativa, compreender o todo satisfatoriamente.

Desse jeito, cada fragmento é independente dos outros e de acordo com Scolari (2013), todos os textos, adaptações ou expansões funcionam como portas de entrada para o universo narrativo. $E$, consequentemente, a possibilidade de a narrativa adquirir mais leitores e/ou espectadores aumenta de acordo com a expansão.

Nesse contexto, ainda é imperativa a coesão entre os conteúdos, ou entre as histórias integrantes da grande história. Isso quer dizer que, se não houver uma demonstração ao público da clara coesão entre as mais diversas partes da história em suas respectivas plataformas, não será possível o sujeito desfrutar plenamente da obra. Outro fator que motiva o público a experimentar intensamente a narrativa é a possibilidade da participação, seja com mensagens ou com coautorias de certas histórias complementares ou mesmo da principal.

Giovagnoli (2011, p. 17), afirma que: “fazer transmídia significa permitir múltiplas mídias contarem histórias diferentes, mas todas explorando um tema comum, mesmo que seja experimentado através de diferentes perspectivas da narrativa". Certamente, o fator mais importante dessa estratégia está na condição de atingir um público que não se satisfaz exclusivamente com um único meio de comunicação e que não está mais disposto em apenas utilizar conteúdos de forma passiva e sim de utilizá-los ativamente, explorando e produzindo. 
Contar uma história transmídia envolve um desses dois processos: ou você tem uma história única que é dividida em diversas mídias, ou você começa com uma história e adiciona pedaços a ela (ad infinitum). Esses dois processos resultarão em projetos que podem ser descritos com frases como: 'melhor que a soma das partes' e 'uma história única e coesa'. (PHILLIPS, 2012, p. 15).

O conceito de Narrativa Transmídia definido por Andrea Phillips (2012) contempla de maneira ampla e objetiva, respectivamente, esse processo. O projeto estruturado pela Narrativa Transmídia estabelece, primeiramente, o roteiro e a sua divisão em partes; em seguida define quais plataformas receberão que partes do roteiro; e, finalmente, determina quanto tempo cada plataforma ficará à disposição do público e como ele poderá participar e/ou articular as narrativas.

Ainda, em consideração a conceituação dada pela autora, além da divisão de uma história e disponibilização de suas partes em diferentes plataformas de mídia, a Narrativa Transmídia pode ser construída a partir de uma história primária que deixa possibilidades de expansão no decorrer de sua narrativa. Dessa maneira, o próprio autor ou os leitores/consumidores podem expandir a história, criando narrativas paralelas a esta e essas expansões sendo disponibilizadas em diferentes mídias. No caso dos leitores/consumidores, ao produzirem histórias expansivas para estas, eles se tornariam coautores do produto cultural.

Para Moraes e Santos (2013), a Narrativa Transmídia no entretenimento, na comunicação mercadológica, no jornalismo ou na educação pode ser considerada uma potência para o engajamento do sujeito no universo do produto cultural que está em diferentes plataformas ou que está sendo expandido e disponibilizado em diferentes plataformas: "os atores do processo comunicacional deixam de ser emissores e receptores e são considerados interlocutores e produtores de uma narrativa complexa". (MORAES; SANTOS, 2013, p. 22).

Isso significa que, com o crescimento da oferta de conteúdos graças à web, o público vem buscando informação e entretenimento em mais de uma plataforma, às vezes até simultâneas e a estratégia da Narrativa Transmídia vem cumprindo esse papel. $\mathrm{O}$ aparente ponto negativo, para os elaboradores desses produtos culturais, é a impressão de que há mais trabalho, porque se produz mais conteúdo, mas que é rapidamente desfeita quando se percebe que a estratégia alcança um público muito maior. A participação do público na construção da narrativa e a possibilidade de atingir um maior número de sujeitos são pensadas por Massarolo e Mesquita (2013):

O mundo de histórias da narrativa transmídia promove a imersão das audiências em novas formas de experiências, nas quais as histórias mais significativas reforçam a noção de pertencimento a um universo narrativo mais amplo. Assim, uma história ao ser desdobrada para outras mídias é compartilhada por novas audiências. (MASSAROLO; MESQUITA, 2013, p. 36).

Ao considerar a informação acima, pensa-se na inserção desse processo que contempla a Narrativa Transmídia, na educação. No contexto da cultura atual, para que o processo de ensino e de aprendizagem possa ser significativo, eficaz e efetivo, as instituições devem desenvolver um sistema acadêmico moderno, que esteja de acordo com as necessidades atuais do ensino e da aprendizagem, bem como dos sujeitos aprendizes. Para isso, sabe-se que é imprescindível o uso de tecnologias digitais, mídias e metodologias que "conversem" com a forma de aprendizagem dos sujeitos inseridos nessa cultura digital. (FAVA, 2014). 
Assim, pensa-se no uso de elementos da Transmídia (criação de novas histórias, expansão da narrativa original para outras mídias, coautoria, participação/engajamento com o universo da narrativa) no processo de aprendizagem. Com base nisso, pensou-se, para este estudo, a inserção desses elementos na metodologia de ensino do conteúdo Gêneros Textuais, engajado à prática da leitura e da escrita.

No contexto atual em que os sujeitos culturais estão inseridos, os elementos citados acima fazem parte de seus cotidianos. Vivem, hoje, em constante interação com o mundo, consumindo e produzindo conteúdos de diversas espécies e para diversos fins. Dessa forma, defende-se a ideia de que, se a educação é item inerente na vida dos sujeitos, esta deve se adequar à realidade do contexto mencionado, pois é a realidade atual.

Quase todas as atividades humanas estão hoje mediadas pelas tecnologias digitais. Longe de ser um meio restrito à interação, abre, antes de tudo, um enorme potencial para a produção e a criação. O computador, com seus programas inteligentes, é dotado de princípios operativos ligados à produção criativa tanto no campo de todas as artes quanto no da literatura. (SANTAELLA, 2013, p. 206).

Portanto, entende-se que o uso desse potencial para a produção e criação de conteúdo disseminado pelas mídias, mudou o comportamento dos sujeitos envolvidos com estas. Espera-se que ao fazer uso, em suas metodologias, dos elementos da transmídia mencionados, os docentes estarão engajando os discentes ao conteúdo por meio da realidade em que estes vivem.

Segundo Fava (2014), vive-se na era da Educação 3.0, mas as instituições de ensino ainda não levaram essa realidade para o seu interior. Para chegar nesta, passou-se pela Educação 1.0, esta consistia no sistema educacional comandado pela Igreja no período Medieval, as escolas nessa época tinham a finalidade de formar eclesiásticos. Centrava-se em uma educação estritamente cristã, por meio da qual se tinha no currículo escrituras, leituras e estudos dos salmos.

A Educação 2.0 está relacionada à Revolução Industrial, assim como a indústria, a educação deveria ser padronizada (homogeneização entre os alunos), especializada (professores, disciplinas e conteúdos especializados, dificultando a relação com outros), concentrada (aprendizagem acontece apenas na sala de aula), centralizada (professor como responsável por ensinar ao aluno) e sincronizada (data e hora determinados para a aprendizagem), princípios tayloristas fortemente arraigados no sistema escolar. (FAVA, 2014). E o que se vê, ainda hoje, em tempos de Educação 3.0, é um sistema escolar fadado a utilizar esses princípios nas instituições de ensino.

Para elucidar a desconexão da Educação 2.0 definida por Rui Fava com a sociedade atual, lavar-se-á em consideração o que afirma Barbero (2014, p. 121), saiu-se de uma "sociedade com sistema educativo para uma sociedade do conhecimento e aprendizagem contínua, isto é, sociedade cuja dimensão educativa atravessa tudo: o trabalho e o lazer, o escritório e a casa, a saúde e a velhice". Sendo assim, o sistema educativo pregado na Educação 2.0 não condiz mais com a realidade dos sujeitos. Na situação atual, o compartilhamento, troca, disseminação de informações são contínuos e com a proliferação das tecnologias digitais, além de contínuo, esse fenômeno tornou-se instantâneo. 
Dessa maneira, em contraposição aos princípios presentes na Educação 2.0, os sujeitos da cultura atual aprendem de forma não padronizada, pois cada um tem suas dificuldades e necessidades específicas, conhecimentos e experiências diferentes; não especializadas, pois existe, assim, a possibilidade de interação entre diferentes conteúdos; não concentrada, pois a aprendizagem acontece em qualquer lugar, não apenas na sala de aula; não centralizada, afinal, o professor não é mais o único responsável por ensinar ao sujeito, ele tem diversas possibilidades de buscar seu próprio conhecimento; e não sincronizada, pois a aprendizagem acontece em qualquer dia e em qualquer hora.

A educação não pode ser fechada em um único local e tempo, o conhecimento não está mais centrado apenas no livro. A aprendizagem não acontece apenas no espaço escolar e o tempo de aprender não é apenas o da idade determinada para o curso de processo seriado de aprendizagem e, sim, durante toda e qualquer idade. A sociedade de educação e aprendizagem contínua associa-se ao descentramento, conhecimento além do livro, deslocalização, a aprendizagem além dos muros da escola e a destemporalização, não há tempo para aprender. (BARBERO, 2014). Essa sociedade de aprendizagem contínua mencionada por Barbero (2014) é a sociedade que contempla a Educação 3.0 definida por Rui Fava (2014).

Mediante isso, o meio educacional deve abrir espaço para mudanças, e não continuar com uma educação pensada para sujeitos que viviam em uma cultura diferente. No contexto atual, pensa-se a Narrativa Transmídia como diversas linguagens que podem ser aderidas pela educação a partir de metodologias elaboradas, fazendo uso dessa. Uma vez que faz uso de elementos como mídias, geralmente digitais, colaboração, criação de histórias/conteúdos, estes, pode-se considerar que engajam o sujeito no conteúdo, o que seria vantajoso para o sistema educacional.

Por isso, propõe-se a inserção dessa realidade no ensino e aprendizagem, dando ênfase ao ensino de Língua Portuguesa. De maneira que se trabalha o conteúdo Gêneros Textuais, elementos da transmídia e literatura. Essa proposta, já apresentada na introdução foi aplicada com alunos do curso de Comunicação Social - Jornalismo de uma Instituição de Ensino Superior (IES) particular e tem resultados apresentados no item que segue.

\section{APLICAÇÃO DE ELEMENTOS DA NARRATIVA TRANSMÍdIA NO PROCESSO DE APRENDIZAGEM}

Nesta seção serão apresentados os dados coletados na parte prática da pesquisa. Pesquisa esta, desenvolvida para embasar reflexões feitas em uma dissertação de mestrado, que tem por objetivo reafirmar as reflexões apresentadas na fundamentação teórica. Dentre estas, a reflexão que norteia toda a pesquisa está relacionada à vantagem trazida pelas tecnologias e mídias por meio de suas funcionalidades para a construção de conhecimento.

Dessa maneira, como proposta, desenvolveu-se uma atividade prática com alunos do curso de Comunicação Social - Jornalismo, utilizando-se elementos da Narrativa Transmídia, para a criação de histórias a partir de um Gênero Textual. A abordagem utilizada na pesquisa é do tipo qualitativa e o método utilizado é o hipotético-dedutivo. Para o desenvolvimento desta prática, fez-se uso da pesquisa-ação. 
[...] a pesquisa-ação procura unir a pesquisa à ação ou prática, isto é, desenvolver o conhecimento e a compreensão como parte da prática. É, portanto, uma maneira de se fazer pesquisa em situações em que também se é uma pessoa da prática e se deseja melhorar a compreensão desta. Mencionar o público pesquisado. Apresentar o desenvolvimento por meio do diário de bordo. (ENGEL, 2000, p. 182).

Dessa forma, justifica-se o uso da pesquisa-ação na segunda etapa da pesquisa. Pois, utilizou-se da discussão teórica feita anteriormente para a reflexão e aplicação da prática. Como afirma Tripp (2005), esse tipo de pesquisa tem a característica de ser cíclica, pelo fato de que se tem a ideia de se aprimorar a prática por meio da intervenção e avaliação dos resultados, uma vez que "planeja-se, implementa-se, descreve-se e avalia-se". (TRIPP, 2005, p. 446). Nesta parte da pesquisa foram seguidos alguns passos: planejamento da atividade, implementação deste junto com os sujeitos pesquisados, descrição das etapas desta implantação e, por fim, avaliação, discutida nas considerações finais desse estudo.

Para o desenvolvimento dessa atividade, realizou-se um contato inicial com os sujeitos pesquisados. Neste, foi aplicado um questionário a estes, no intuito de coletar informações acerca de seus conhecimentos sobre Gêneros Textuais, Crônica e as habilidades comunicativas de leitura e escrita. Após breve análise dos questionários respondidos, em outro momento, realizou-se uma oficina junto com esses alunos participantes da pesquisa.

O universo da pesquisa foi o Comunicação Social - Jornalismo de uma IES particular situada na cidade de Aracaju/SE. Os sujeitos pesquisados são cinco alunos que estão cursando o segundo período. Estes foram selecionadas para a prática pelo fato de estarem fazendo a leitura do romance Capitães da Areia, obra escolhida para o desenvolvimento da atividade por apresentar possibilidades de expansão na extensão do seu enredo, no momento de realização da pesquisa.

Durante a oficina proposta, discutiu-se o conceito de Narrativa Transmídia e também a definição e caracterização da Crônica. Durante a oficina houve interação dos sujeitos, que comentaram acerca dos conteúdos e apresentaram dúvidas, sanadas pelas pesquisadoras. A partir disso, foi explicada a proposta da atividade que eles deveriam desenvolver e foram acompanhados pelas pesquisadoras durante todo o caminho da produção. Nesta atividade, os sujeitos criaram histórias que deram continuidade à narrativa do Romance, utilizando o Gênero Textual Crônica para isso e, ainda, disponibilizaram as produções em uma plataforma de mídia, caracterizando os elementos da Narrativa Transmídia. Ao final da criação das Crônicas, os participantes responderam, novamente, ao mesmo questionário aplicado no início da pesquisa.

$\mathrm{Na}$ etapa em que foi realizada a oficina e desenvolvida a atividade utilizou-se o método de procedimento experimental, por meio de pesquisa-ação, como já foi mencionado. O método escolhido, como próprio nome enfatiza, é fundado na experiência. Ou seja, os sujeitos são colocados em situações de prática previamente planejadas, com hipóteses lançadas. E, então, após a experiência (prática) feita, confirma-se ou refuta-se as hipóteses construídas anteriormente. 
As técnicas de coleta de dados são o questionário fechado, utilizando-se de escala do tipo Likert, e o instrumento que serviu para avaliar as produções com relação à adequação ao gênero proposto (instrumento criado pelas pesquisadoras). De acordo com Paro (2012, p. 1), "a escala Likert é uma escala psicométrica das mais conhecidas e utilizada em pesquisa quantitativa, já que pretende registrar o nível de concordância ou discordância com uma declaração dada".

À vista disso, sustenta-se o uso desse tipo de escala no questionário da pesquisa realizada. Ao utilizar esse tipo de escala para coletar dados por meio de questionário, verifica-se a facilidade de manuseio desta, pois a partir de uma análise das respostas dadas, com critério e atenção, o pesquisador emite um nível sobre o que se afirma ou pergunta por meio do questionário. (SILVA; COSTA, 2014).

Esse percurso metodológico foi desenvolvido com o auxílio de elementos da Narrativa Transmída. Este permitiu avaliar o desenvolvimento do conhecimento dos alunos no que se refere ao Gênero Textual trabalhado. Além disso, avaliou-se também o como variou o desenvolvimento das habilidades comunicativas de leitura e escrita destes sujeitos, segundo eles.

Os resultados coletados serão apresentados com o objetivo de posterior análise. Esta se pautará pelas seguintes categorias: comparação dos questionários respondidos pelos sujeitos antes e após o desenvolvimento da atividade; avaliação das produções destes sujeitos a fim de verificar em qual nível de conhecimento acerca da crônica cada um encaixou após a prática. Com isso, percebeu-se que nos itens referentes aos Gêneros Textuais, no geral, os sujeitos apresentaram estabilidade no nível de conhecimento. A indicação do nível de conhecimento sobre os Gêneros Textuais, por parte deles, foi a mesma antes e após a realização da atividade. Com exceção de dois alunos, no item referente as funções dos Gêneros Textuais, que apresentaram declínio de um nível no conhecimento dessa funcionalidade.

Os dois itens seguintes referem-se ao Gênero Textual Crônica, gênero trabalhado diretamente no desenvolvimento da atividade. A partir da análise desses itens (conhecimento do gênero textual crônica), verificou-se que todos os alunos apontaram acréscimo no nível de conhecimento acerca da Crônica e de suas características. Por fim, questionou-se aos alunos sobre suas habilidades de leitura e escrita. Com relação à leitura, dois alunos enquadram-se em níveis inferiores após a realização da atividade e dois alunos declaram que o nível permaneceu estável, mesmo com a prática de leitura e produção de texto escrito. Por fim, apenas um afirma que o nível desta habilidade aumentou.

Já na habilidade da escrita, não houve casos de decréscimo após a realização da prática, porém três alunos, declaram que não houve alteração dessa habilidade após a atividade. E dois alunos afirmam que o nível em relação a escrita aumentou com a prática de leitura de um romance e produção de uma crônica. Com isso, elucida-se que, segundo a autoafirmação dos sujeitos, houve aprendizagem deste com relação a Crônica. Já com relação a aprendizagem dos Gêneros Textuais, no geral, e o aprimoramento das habilidades de leitura e escrita, houve uma estabilidade, em maioria, e alguns casos de decréscimo no nível de conhecimento. 
Foi desenvolvido um instrumento de coleta de dados utilizando características do Gênero Textual Crônica segundo Moisés (1994). Com o objetivo de verificar em qual nível de conhecimento acerca deste gênero os sujeitos pesquisados se enquadram, para cada característica citada, há as opções "Atendeu" e "Não atendeu" a serem assinaladas. Verificada as dez características, a avaliação pode ser enquadrada em seis níveis: 1) Atendeu os dez itens = Conhecimento excelente acerca do gênero; 2) Atendeu entre sete e nove dos dez itens = Conhecimento bom acerca do gênero; 3) Atendeu entre quatro e seis dos dez itens = Conhecimento intermediário acerca do gênero; 4) Atendeu entre dois e três dos dez itens = Conhecimento fraco acerca do gênero; 5) Atendeu um dos dez itens = Conhecimento precário acerca do gênero; 6) Não atendeu a nenhum dos itens = Não possui conhecimento acerca do gênero. Para esta avaliação, os alunos serão denominados como "aluno A", "aluno B", "aluno C", "aluno D" e "aluno E". Assim, os dados coletados mostram que:

Das dez características do gênero apresentadas no instrumento, o aluno $A$ atendeu a sete. Dessa forma, segundo avaliação do instrumento, o aluno foi enquadrado no nível 2, o que significa que este tem um conhecimento bom acerca do gênero. Durante o processo, aluno A interagiu tirando dúvidas no encontro presencial, no qual foram explicados a proposta, bem como os conceitos trabalhados. $O$ aluno $B$, das dez características do gênero apresentadas no instrumento, atendeu a cinco. Dessa forma, segundo avaliação do instrumento, o aluno foi enquadrado no nível 3 , o que significa que este tem um conhecimento intermediário acerca do gênero.

Em continuidade, das dez características do gênero apresentadas no instrumento, o aluno $\mathrm{C}$ atendeu a oito. Dessa forma, segundo avaliação do instrumento, o aluno foi enquadrado no nível 2, o que significa que este tem um conhecimento bom sobre o gênero. Este aluno participou bastante das discussões no encontro presencial. Já o aluno $D$ atendeu a nove das dez características do gênero apresentadas no instrumento. Assim, segundo avaliação do instrumento, o aluno foi enquadrado no nível 2, o que significa que este tem um conhecimento bom acerca do gênero. Este sujeito foi o que mais participou do processo desde o início, tirando dúvidas e participando das discussões no encontro presencial. $O$ que pode ser considerado fator relevante para o bom desempenho na construção do texto.

Por fim, das dez características do gênero apresentadas no instrumento, o aluno $E$ atendeu a quatro. Dessa forma, segundo avaliação do instrumento, o aluno foi enquadrado no nível 3, o que significa que este tem um conhecimento intermediário acerca do gênero. $O$ aluno $E$ fez algumas perguntas durante a discussão que aconteceu no encontro presencial. Após a avaliação das crônicas dos alunos participantes da pesquisa, foi possível perceber um resultado em que três nos cinco alunos foram enquadrados no conhecimento bom acerco da Crônica, os outros dois ficaram no conhecimento de nível intermediário. Com isso, percebeu-se que os alunos que interagiram durante a oficina, apresentando seus conhecimentos nas discussões e tirando dúvidas, tiveram um melhor desempenho do que os dois que não se manifestaram durante o processo.

Enfim, a proposta da inclusão do processo transmídia na prática do uso de Gêneros Textuais, entrelaçando-a em atividades de leitura e escrita, teve o intuito de apresentar novas 
possibilidades ao processo de aprender. Desta forma, contrapondo-se ao discurso de alguns sujeitos que afirmam que o desinteresse das novas gerações pela leitura é influenciado pelos meios audiovisuais.

Afirma-se, dessa forma, que essa característica de autoria engajou os sujeitos de maneira significativa, pois estes aproximaram-se do conteúdo para poder produzir o que foi solicitado, tanto do conteúdo do romance como do conteúdo referente ao gênero textual trabalhado, bem como desenvolveram as habilidades de leitura e escrita por meio da prática. Uma vez que estes produziram um texto próprio, ou seja, autoral, preocuparam-se em construir um conteúdo de qualidade, que seja consumido por muitos outros sujeitos. Assim, defende-se que essa possibilidade de o sujeito virar autor de determinado conteúdo, aproxima-o, ainda mais, do conteúdo consumido para criar o desdobramento, como já foi mencionado, assim como das temáticas que envolvem estes conteúdos, tanto o consumido, como o produzido.

\section{CONSIDERAÇÕES FINAIS}

Embora sugiram serem contemporâneas ou inovadoras, as narrativas transmídias moldamse em um princípio secular. Secular porque é na essência do fenômeno da transmidiação que se pode evidenciar um dos principais aspectos da prática dos sujeitos: a extensão de conteúdos. 0 ato de trabalhar e propor abordagens diferentes para um conteúdo específico inaugura uma espécie de singularidade para os conteúdos afetados, ao passo em que transforma as concepções de outros sujeitos no que tange a informação mãe ou o próprio conteúdo transmidiático. Pelo seu teor genuinamente extensivo, essas narrativas impulsionam o sujeito a pôr em foco a observação, o contato, e a interpretação, mas sobretudo, a criação do seu próprio conteúdo. Isto é, hoje esse sujeito não somente consome informação, mas produz, designando-se assim, como um sujeito autor.

Este contexto discute como as práticas que considerem a imaginação e a criatividade podem ser benéficas e relevantes para o desenvolvimento do sujeito (muito embora sejam pouco consideradas no campo formal de ensino). Parte-se da fenomenologia de Peirce (1999) para lembrar que, qualquer que seja o processo que encaminhe o sujeito a um relevo de raciocínio psíquico, este é essencialmente decisivo. Mas é decisivo porque, partindo do estudo dos signos, na direção do processo interpretativo, tem-se a primeiridade (o impacto com o objeto), a secundidade (o nível energético que irá transladar ao raciocínio final) e a terceiridade (etapa final que efetiva o juízo crítico deste sujeito em relação ao conteúdo) que, sob face dessas etapas, existe o consciente do sujeito trabalhando para manter contato com os signos.

Então, é possível ressaltar que, qualquer que seja a atividade, mais especificamente no caso da produção transmídia, existe um processo tanto íntimo, quanto energético, e finalmente, crítico. Nesse fato, poder-se-ia dizer que, ao pensar, se engajar e produzir um conteúdo, o sujeito traduz um processo mais atípico e sobressalente, especialmente no que se refere à aprendizagem. 
Em união às mídias essa aprendizagem se torna mais extensa e ampla, como é o caso da atividade colaborativa. Cada um sendo autor da sua própria história, interagindo, e aprendendo com os outros autores. É nessa perspectiva que se apoia a atividade apresentada aos alunos do curso de Jornalismo.

Evidencia-se assim que, a adoção de novos métodos possivelmente resulte promissora, mas é adequado refletir acerca de como tal adoção pode contribuir e ampliar um processo pedagógico. O diálogo entre dois universos (conteúdo original e conteúdo transmidiático criado por um sujeito a partir do original) somados à atividade colaborativa, e a inserção de um novo conteúdo no processo, em sua essência, aponta para um caminho de potencialidade de habilidades, engajamento, construções e dinâmica entre sujeito e conteúdo.

Em adesão, diante deste cenário, se torna proeminente assinalar sobre a ideia possivelmente rasa em relação à falta de fomento à escrita e leitura efetuadas pela invasão das mídias. Como contraponto tem-se o que Jenkins (2012) lembra sobre escrita criativa e leitura. Hoje, as narrativas transmídias instalam uma nova perspectiva para os processos de leitura e escrita, isto é, tendem a fomentar e enaltecer essas habilidades, abrindo espaço para uma ação mais construtiva.

Quando a transmidiação se aplica na prática pedagógica é provável lançar o foco da conexão entre distintos campos de conhecimento, o que, por sua vez, revela-se positivo em função de conferir novo pensamento sobre tais conteúdos. No entanto, esse diálogo igualmente aponta que não se faz preciso abandonar métodos tradicionais de ensino, mas abrir perspectiva para que um teor informal e a imaginação e criatividade do sujeito sejam postos em presença.

Nesse sentido, de acordo com os dados coletados na parte prática da pesquisa, afirma-se que a proposta de inclusão de elementos da transmídia em união à prática de produção dos gêneros textuais e, consequentemente, a prática de leitura, adquiriram um teor expressivo no que compete ao desempenho dos sujeitos imersos. Verificou-se que, em relação à aprendizagem do Gênero Textual Crônica todos os sujeitos tiveram elevação no nível de conhecimento acerca deste conteúdo. Elucida-se isso mesmo havendo casos de nível de conhecimento intermediário na avaliação das crônicas, pois não foi feita uma avaliação anterior da produção deste gênero junto aos alunos. Anteriormente, foi respondido apenas aos questionários por estes sujeitos e, a partir disso, assegura-se que houve desenvolvimento no nível de conhecimento dos sujeitos acerca do gênero trabalhado.

Ao considerar ao desenvolvimento da leitura e da escrita desses sujeitos, eles afirmaram, por meio dos questionários, que estas habilidades se mantiveram estáveis e, ainda, alguns responderam ao questionário de forma que após a prática houve um decréscimo dessas habilidades. Dessa maneira, acredita-se que se chegou a esses resultados, relacionados a leitura e a escrita, pelo fato da prática ter sido restrita a apenas um gênero, enquanto o questionamento feito no questionário ter sido feito com relação a qualquer tipo e gênero de texto.

Por fim, reafirma-se que a inserção de elementos da Narrativa Transmídia na prática de leitura e de produção de gêneros textuais apresenta contribuições para o processo de 
aprendizagem do gênero trabalhado, bem como para a prática de leitura e de produção deste mesmo gênero. Como contribuições, entende-se o engajamento do sujeito aos conteúdos trabalhados no contexto e o consequente desenvolvimento da aprendizagem destes em relação a esses conteúdos, bem como o desenvolvimento da independência do sujeito nesta aprendizagem. Além disso, elucida-se a posição de autor de conteúdo que geram um sentido mais promissor em torno do processo de aprendizagem destes sujeitos.

\section{REFERÊNCIAS}

Argan, G. (1998). História da arte como história da cidade (4a ed.). São Paulo: Martins Fontes.

Barbero, J. (2014). A comunicação na educação. São Paulo: Contexto.

Bruns, A. (2008). Blogs, Wikipedia, Second Life, and Beyond from production to produsage. New York: Peter Lang.

Canclini, N. (1997). Culturas híbridas y estrategias comunicacionales. Estudios sobre las Culturas Contemporaneas, Colima, 3(5), 109-128.

Castells, M. (2001). La galaxia internet. Madrid: Areté.

Castells, M., \& Cardoso, G. (2005). A sociedade em rede: do conhecimento à acção política. Recuperado em 20 maio, 2016, de http://biblio.ual.pt/Downloads/REDE.pdf. Acesso em: 20 mai. 2016.

Caune, J. (2014). Cultura e comunicação: convergências teóricas e lugares de mediação. São Paulo: Editora Unesp.

Citelli, A. (2004). Comunicação e educação: a linguagem em movimento (3a ed.). São Paulo: Editora Senac São Paulo.

Engel, G. I. (2000). Pesquisa-ação. Educar, Curitiba, (16), p. 181-191.

Fava, R. (2014). Educação 3.0: aplicando o PDCA nas instituições de ensino (1a ed.). São Paulo: Saraiva, 2014.

Freire, P. (2011). Pedagogia da autonomia: saberes necessários à prática educativa (43a ed.). São Paulo: Paz e Terra.

Gaglietti, M., \& Barbosa, M. (2007). A Questão da Hibridação Cultural em Néstor García Canclini. Anais do VIII Congresso Brasileiro de Ciências da Comunicação da Região Sul, 11.

Giovagnoli, M. (2011). Transmedia Storytelling: imagery, shapes e techniques. Pittsburgh: ETC Press.

Gosciola, V. (2012). A máquina de Narrativa Transmídia: transmidiação e literatura fantástica. Revista Comunicación, 1 (10), p. 131-139. Recuperado em 20 maio, 2016, de https://www.researchgate.net/publication/267726995_A_Maquina_de_Narrativa_Transmid ia_transmidiacao_e_literatura_fantastica.

Gosciola, V., \& Versuti, A. (2012). A. Narrativa Transmídia e Sua Potencialidade na Educação 
Aberta. Recuperado em 7 maio, 2016 de http://oer.kmi.open.ac.uk/?page_id=428

Jenkins, H. (2009). Cultura da convergência (2a ed.). São Paulo: Aleph.

Lemos, A. (2002). Cibercultura. Tecnologia e Vida Social na Cultura Contemporânea. Porto Alegre: Sulina.

Lévy, P. Cibercultura (6a ed.). Editora 34 Ltda.: São Paulo.

Macedo, A. (2012). Cultura: está na hora da mudança. Recuperado em 7 maio, 2016 de http://tribunaamapaense.blogspot.com.br/2012/05/cultura-esta-na-hora-da-mudanca.html.

Martins, C. (2009). A cultura da convergência e a narrativa transmídia. Opinião \& Notícia. Recuperado em 10 maio, 2016 de http://opiniaoenoticia.com.br/vida/tecnologia/a-culturada-convergencia-e-a-narrativa-transmidia/

Massarolo, J.; Mesquita, D. (2013). Narrativa transmídia e a Educação: panorama e perspectivas. Ensino Superior Unicamp, Especial, 34-42.

Moisés, M. (1994). A criação literária: prosa 2 (15a ed.). São Paulo: Cultrix.

Moraes, E., \& Santos, M. (2013). O jornalismo como narrativa transmídia: reflexões possíveis. In D. Renó, C. Campalans, S. Ruiz \& V. Gosciola (Ed(s)). Periodismo transmedia: miradas múltiples. Bogotá: Editorial Universidad del Rosário.

Moran, J. (2007). As mídias na educação. In J. Moran. Desafios na Comunicação Pessoal (3a ed.). São Paulo: Paulinas.

Neiva, E. (2013). Dicionário Houaiss de comunicação e multimídia. São Paulo: Publifolha.

Paro, B. (2012). A escala Likert - coisas que todo pesquisador deveria saber. Recuperado em 6 junho, 2016 de http://www.netquest.com/blog/br/a-escala-likert-coisas-que-todopesquisador-deveria-saber/

Peirce, C. (1999). Semiótica. São Paulo: Perspectiva.

Penteado, J. (1987). A técnica da comunicação humana (10a ed.). São Paulo: Pioneira.

Phillips, A. (2012). A creator's guide to Transmedia Storytelling: how to captivate and engage audiences across multiple platforms. New York: McGraw-Hill.

Porto, C. (2012). Internet e comunicação científica no Brasil: Quais impactos? Quais mudanças?. Salvador: EDUFBA.

Rousseau, J. (1998). Ensaio sobre a origem das línguas. São Paulo: Editora da Unicamp.

Santaella, L. (2013). Comunicação ubíqua: repercussões na cultura e na educação. São Paulo: Paulus.

Santana, M. (2002). Conversa desautorizada: a importância da nova retórica pra o administrador contemporâneo. Monografia, Faculdade de Tencologias e Ciências - FTC, Feira de Santana, Bahia, Brasil.

Scolari, C. (2013). Narrativas Transmedia: Cuando todos los medios cuentan. Barcelona: Deusto S.A.

Silva, S., Jr., \& Costa, F. (2014). Mensuração e Escalas de Verificação: uma Análise Comparativa das 
Escalas de Likert e Phrase Completion. Revista Brasileira de Pesquisas de Marketing, Opinião e Mídia, São Paulo, 15, p. 1-16.

Silverstone, R. (2002). Por que estudar a mídia? São Paulo: Edições Loyola.

Toffler, A. (1980). The third wave. New York: Bantam.

Tripp, D. (2005). Pesquisa-ação: uma introdução metodológica. Educação e Pesquisa, São Paulo, 31 (3), 443-466.

Versuti, A., Gosciola, V., \& Lima, D. (2014). Propostas de recursos educacionais abertos em narrativas transmídia. In C. Porto \& A. Versuti (Orgs.). Multiplicidades e redimensionamentos na educação contemporânea. Salvador: EDUFBA. 